\title{
The Characteristics of Renal Hypoperfusion in Dogs with Acute and Chronic Reductions in Glomerular Filtration Rate as Disclosed by the Pattern of Water and Solute Excretion after Hypotonic Saline Infusions *
}

\author{
George Van Giesen, $\dagger$ Merrick Reese, Fredrik Kill, $\dagger$ Floyd C. Rector, Jr., \\ and Donald W. Seldin \\ (From the Department of Internal Medicine, the Unizersity of Tcras Southicstern Medical \\ School, Dallas, Texas)
}

Under ordinary circumstances the elaboration of a dilute urine is dependent upon suppression of the secretion of antidiuretic hormone $(\mathrm{ADH})$. Even when $\mathrm{ADH}$ secretion is maximally suppressed, however, a concentrated urine may be formed. Berliner and Davidson (1), del Greco and de Wardener (2), and Kleeman, Maxwell, and Rockney (3) have demonstrated that a reduction in glomerular filtration rate (GFR) can result in the excretion of hypertonic urine in the absence of $\mathrm{ADH}$ activity.

The factors responsible for urinary hypertonicity under these conditions have not been completely elucidated. Del Greco and de Wardener (2) have attributed the hypertonicity to the effects of diminished total solute excretion. Berliner and Davidson (1), on the other hand, regard the hypertonicity as the result of reduced delivery of sodium salts to the diluting segment, in consequence of which free water formation is drastically reduced; if the distal portions of the nephron in the absence of $\mathrm{ADH}$ were even minimally permeable to water, back diffusion of only a small amount of free water would then render the urine hypertonic. However, Leaf, Kerry, Wrong, and Chatillon (4) failed to demonstrate any rise in urinary tonicity during water diuresis despite significant reductions in GFR.

* Submitted for publication August 7, 1963; accepted November 7, 1963.

This work was supported in part by U. S. Public Health Service grants HTS-5469 and 2A-5028.

† Postdoctoral fellow under U. S. Public Health Service training grant 2A-5028. Present address: Department of Internal Medicine, Medical College of Georgia, Augusta, Ga.

\$ Present address: Institute for Experimental Medical Research, Ullevaal Hospital, Oslo, Norway.
The present experiments were designed to examine the role of GFR, solute excretion, and sodium excretion on urinary tonicity when $\mathrm{ADH}$ activity is negligible. To determine whether acute reductions in GFR produce effects that are then obscured by adaptative changes, studies in which GFR was reduced for periods up to three months were also undertaken.

\section{Materials and Methods}

Female mongrel dogs, weighing 10 to $17 \mathrm{~kg}$ and fed regular commercial diets, were used in all studies. The effects of acute and chronic reductions in GFR on the excretion of water and solutes were studied during water diuresis and during hypotonic saline diuresis.

Acute reductions in GFR were produced in four dogs by inflating a balloon in the thoracic aorta. After the dogs were anesthetized with sodium pentobarbital, a balloon connected to an arterial catheter was inserted through the right brachial artery into the thoracic aorta to a point just above the renal arteries. Inflation of the balloon so that femoral arterial pressure was reduced by about $50 \%$ reproducibly depressed GFR by about $30 \%$. Urine was collected from an indwelling bladder catheter. Blood was collected with a Cournand needle in the femoral artery through which blood pressure was also monitored.

The studies were then carried out in the following order (Table I). First, diuresis was initiated by the administration of 1 to $1 \frac{1}{2} \mathrm{~L}$ of water by stomach tube and sustained by the infusion of $2 \%$ glucose in water at a rate of $3 \mathrm{ml}$ per minute. After urine flow had stabilized, two or three control periods were obtained Second, the balloon was inflated, and observations were continued for three additional periods. Third, the balloon was then deflated, and two recovery periods werc obtained. (Within 10 to 20 minutes after deflation of the balloon, GFR, urine flow, and urinary composition uniformly returned to the values of control periods.) Fourth, while the $2 \%$ glucose infusion was continued, an infusion of $0.45 \%$ sodium chloride was administered at rates of from 15 to $25 \mathrm{ml}$ per minute. When the urine 
TABLE I

Protocol of representative experiment (dog 11) showing the effects of acute reductions in GFR on urine flow and composition during water diuresis and hypotonic saline diuresis*

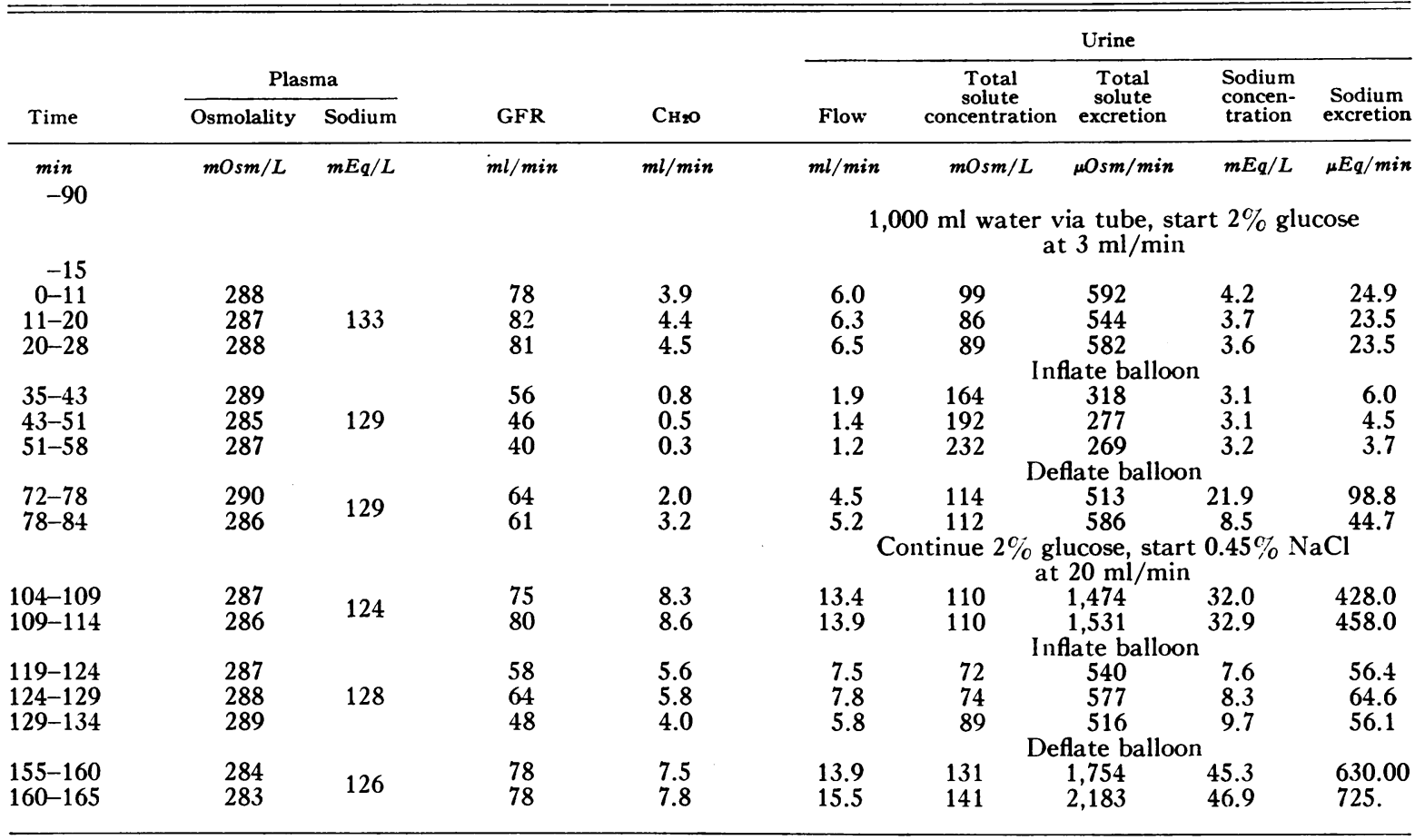

${ }^{*} \mathrm{GFR}=$ glomerular filtration rate $; \mathrm{C}_{\mathrm{H}_{2} \mathrm{O}}=$ clearance of solute-free water.

flow approximated at least $10 \mathrm{ml}$ per minute, two control periods were obtained. Fifth, the balloon was reinflated to the same extent as previously and subsequent periods obtained. Finally, the balloon was deflated and two recovery urine samples collected.

Chronic reductions in GFR were performed by constricting either the left renal artery or the aorta between the renal arteries. A bladder-splitting operation was first performed to permit the separate collection of urine from each kidney through funnel-shaped Teflon tubing inserted into each hemibladder (1). To exclude the dogs with urinary tract obstruction, GFR was measured so that equality of function of each kidney could be ascertained. A second operation was performed 7 to 10 days after the bladder-splitting operation. Through either an abdominal or flank incision, a 4-0 silk ligature was placed around the aorta between the renal arteries or around the left renal artery alone. After a mannitol diuresis of 6 to $8 \mathrm{ml}$ per minute was established, the vessel was constricted so that urine flow from the constricted side was 50 to $60 \%$ less than that from the normal side. In extensive preliminary studies we had determined that this procedure resulted in a degree of constriction that usually reduced GFR by 10 to $30 \%$.

In six experiments on five dogs, the effects of both water and hypotonic saline diuresis were studied in the same sequence previously outlined for the studies during acute reductions in GFR (Table III). (Hypotonic sa- line alone was administered in two, and water alone in three, additional experiments.) In these chronic studies, the constricted side was compared with the normal side.

Inulin clearance was measured by infusing inulin at 10 mg per minute after a priming dose of $1 \mathrm{~g}$. The concentration of inulin in urine and blood was determined by the method of Walser, Davidson, and Orloff (5). Sodium was determined with an internal standard flame photometer, and osmolalities of urine and plasma were measured on a Fiske osmometer.

\section{Results}

Acute reductions in GFR. Experiments during water and hypotonic saline diuresis were performed on four dogs. The data presented in Table I are from a representative dog; all the studies are summarized in Table II. During water diuresis GFR was relatively constant, urine flow was slightly greater than $6 \mathrm{ml}$ per minute, and urine osmolality was below 100 mOsm per L (Table I). When the aortic balloon was inflated, there was a reduction in GFR (about 40\%), urine flow, and free water clearance $\left(\mathrm{C}_{\mathrm{H}_{2} \mathrm{O}}\right)$. On the other hand, urine osmolality rose from 89 to a high of 232 
mOsm per $\mathrm{L}$, but urine sodium concentration fell slightly, from 3.6 to $3.1 \mathrm{mEq}$ per $\mathrm{L}$. When the balloon was deflated, GFR returned toward control values, as did urine flow, $\mathrm{C}_{\mathrm{H}_{2} \mathrm{O}}$, urine osmolality, and urine sodium concentration. While $2 \%$ glucose was continued, $0.45 \%$ sodium chloride was begun intravenously at $20 \mathrm{ml}$ per minute. GFR returned to the values obtained during the initial periods of water diuresis, whereas urine flow increased to slightly greater than $13 \mathrm{ml}$ per minute, $\mathrm{C}_{\mathrm{H}_{2} \mathrm{O}}$ doubled, urine osmolality remained at $110 \mathrm{mOsm}$ per $\mathrm{L}$, and urine sodium concentration rose to $32 \mathrm{mEq}$ per $\mathrm{L}$. Under these conditions, inflation of the balloon resulted in similar percentage reductions in GFR, urine flow, and $\mathrm{C}_{\mathrm{H}_{2} \mathrm{O}}$ as during water diuresis; but now, there was a decrease in urine osmolality, as contrasted with the rise in osmolality during water diuresis. In addition, urine sodium concentration was sharply reduced, from 32 to $8 \mathrm{mEq}$ per $\mathrm{L}$ (about 75\%). When the balloon was deflated, all values returned to those obtained during the preinflation periods.

Table II charts the mean values for GFR, urine flow, urine sodium concentration and excretion, and urine osmolality in the four dogs in which aortic pressure was reduced by inflation of the aortic balloon. The percentage of change (positive or negative) from control values is also recorded for each parameter of renal function. During water diuresis, inflation of the balloon re- sulted in a mean decrease in GFR of $29 \%$ and a mean decrease in urine flow of $73 \%$. Mean sodium excretion fell by $76 \%$, but mean urine sodium concentration fell by only $19 \%$. Moreover, this decrease in urine sodium concentration represents an actual mean fall of only $1.2 \mathrm{mEq}$ per L. Mean urine osmolality rose $103 \%$. During hypotonic saline diuresis, inflation of the balloon resulted in reductions in GFR virtually identical to those obtained during water diuresis. However, the fall in urine sodium concentration after reduction of GFR was greatly enhanced by the infusion of hypotonic saline. Whereas reduction in GFR produced a mean fall of only $19 \%$ during water diuresis, the mean fall during hypotonic saline diuresis was $77 \%$. The actual mean fall in sodium concentration was $21.6 \mathrm{mEq}$ per $\mathrm{L}$ during hypotonic saline compared with only $1.2 \mathrm{mEq}$ per L during water diuresis. Furthermore, in contrast to the rise in urine osmolality during water diuresis, a reduction in GFR lowered urine osmolality during hypotonic saline diuresis.

Chronic reductions in GFR. In six studies on five dogs, the effects of both water diuresis and hypotonic saline diuresis were compared; additional unpaired experiments included three studies with water diuresis alone and two studies with hypotonic saline diuresis alone (Tables III and IV). The data presented in Table III are from a representative $\operatorname{dog}$ in which the left renal artery

TABLE III

Protocol of representative experiment (dog 8$)$ showing the effects of chronic reductions in GFR on urine flow and composition during water diuresis and hypotonic saline diuresis

\begin{tabular}{|c|c|c|c|c|c|c|c|c|c|c|c|c|c|c|c|c|}
\hline \multirow[b]{3}{*}{ Time } & \multirow{2}{*}{\multicolumn{2}{|c|}{ Plasma }} & \multirow{2}{*}{\multicolumn{2}{|c|}{ GFR }} & \multirow{2}{*}{\multicolumn{2}{|c|}{$\mathrm{C}_{\mathrm{H}_{2} \mathrm{O}}$}} & \multicolumn{10}{|c|}{ Urine } \\
\hline & & & & & & & \multicolumn{2}{|c|}{ Flow } & \multicolumn{2}{|c|}{$\begin{array}{c}\text { Total } \\
\text { solute } \\
\text { concentration }\end{array}$} & \multicolumn{2}{|c|}{$\begin{array}{c}\text { Total } \\
\text { solute } \\
\text { excretion }\end{array}$} & \multicolumn{2}{|c|}{$\begin{array}{l}\text { Sodium } \\
\text { concen- } \\
\text { tration }\end{array}$} & \multicolumn{2}{|c|}{$\begin{array}{l}\text { Sodium } \\
\text { excretion }\end{array}$} \\
\hline & $\begin{array}{l}\text { Osmo- } \\
\text { lality }\end{array}$ & $\begin{array}{c}\text { So- } \\
\text { dium }\end{array}$ & $\mathrm{R}^{*}$ & $\mathrm{~L}^{*}$ & $\mathbf{R}$ & $\mathbf{L}$ & $\mathbf{R}$ & $\mathbf{L}$ & $\mathbf{R}$ & $\mathbf{L}$ & $\mathbf{R}$ & $\mathbf{L}$ & $\mathbf{R}$ & L & $\mathbf{R}$ & $\mathbf{L}$ \\
\hline $\begin{array}{l}\min \\
-90\end{array}$ & $\underset{L}{m O s m /}$ & $\begin{array}{c}m E q / \\
L \\
146.5\end{array}$ & \multicolumn{2}{|c|}{$m l / m i n$} & \multicolumn{2}{|c|}{$m l / m i n$} & \multicolumn{2}{|c|}{$m l / m i n$} & \multicolumn{2}{|c|}{$m O s m / L$} & \multicolumn{2}{|c|}{$\mu E q / \min$} & \multicolumn{2}{|c|}{$m E q / L$} & \multicolumn{2}{|c|}{$\mu E q / \min$} \\
\hline $\begin{array}{r}-15 \\
20-30 \\
30-40 \\
40-50 \\
50-60\end{array}$ & $\begin{array}{l}283 \\
289 \\
285 \\
285\end{array}$ & & $\begin{array}{l}29 \\
28 \\
28 \\
27\end{array}$ & $\begin{array}{l}27 \\
23 \\
23 \\
24\end{array}$ & $\begin{array}{l}2.4 \\
2.2 \\
2.4 \\
1.4\end{array}$ & $\begin{array}{l}0.6 \\
0.6 \\
0.6 \\
0.8\end{array}$ & $\begin{array}{l}3.9 \\
3.6 \\
3.7 \\
4.3\end{array}$ & $\begin{array}{l}1.6 \\
1.4 \\
1.4 \\
1.8\end{array}$ & $\begin{array}{r}110 \\
110 \\
100 \\
90\end{array}$ & $\begin{array}{l}167 \\
161 \\
173 \\
154\end{array}$ & $\begin{array}{l}429 \\
396 \\
370 \\
387\end{array}$ & $\begin{array}{l}267 \\
225 \\
294 \\
293\end{array}$ & $\begin{array}{r}12.5 \\
8.0 \\
5.4 \\
5.3\end{array}$ & $\begin{array}{l}1.8 \\
1.4 \\
1.7 \\
1.9\end{array}$ & $\begin{array}{l}48.7 \\
28.8 \\
20.0 \\
22.8\end{array}$ & $\begin{array}{l}2.9 \\
2.0 \\
2.4 \\
3.4\end{array}$ \\
\hline 60 & & & \multicolumn{14}{|c|}{ Continue $2 \%$ glucose, start $0.45 \%$ saline at $15 \mathrm{ml} / \mathrm{min}$} \\
\hline $\begin{array}{c}70-80 \\
80-90 \\
90-100 \\
100-110\end{array}$ & $\begin{array}{l}282 \\
283 \\
283 \\
282\end{array}$ & 143.0 & $\begin{array}{l}28 \\
28 \\
28 \\
28\end{array}$ & $\begin{array}{l}23 \\
23 \\
23 \\
22\end{array}$ & $\begin{array}{l}5.9 \\
6.3 \\
6.1 \\
6.1\end{array}$ & $\begin{array}{l}3.6 \\
3.8 \\
3.8 \\
3.7\end{array}$ & $\begin{array}{l}8.9 \\
9.3 \\
9.3 \\
9.1\end{array}$ & $\begin{array}{l}4.7 \\
4.8 \\
4.9 \\
4.8\end{array}$ & $\begin{array}{l}84 \\
92 \\
95 \\
93\end{array}$ & $\begin{array}{l}63 \\
60 \\
63 \\
66\end{array}$ & $\begin{array}{l}748 \\
856 \\
884 \\
846\end{array}$ & $\begin{array}{l}296 \\
288 \\
321 \\
343\end{array}$ & $\begin{array}{l}25.0 \\
30.0 \\
43.5 \\
40.9\end{array}$ & $\begin{array}{l}4.9 \\
4.1 \\
5.1 \\
5.2\end{array}$ & $\begin{array}{l}222.5 \\
279.0 \\
404.5 \\
372.1\end{array}$ & $\begin{array}{l}23.0 \\
19.7 \\
25.0 \\
25.0\end{array}$ \\
\hline
\end{tabular}

${ }^{*} \mathrm{R}=$ right kidney, $\mathrm{L}=$ left kidney. 
TABLE IV

Glomerular hypoperfusion as disclosed by water diuresis and hypotonic saline diuresis*

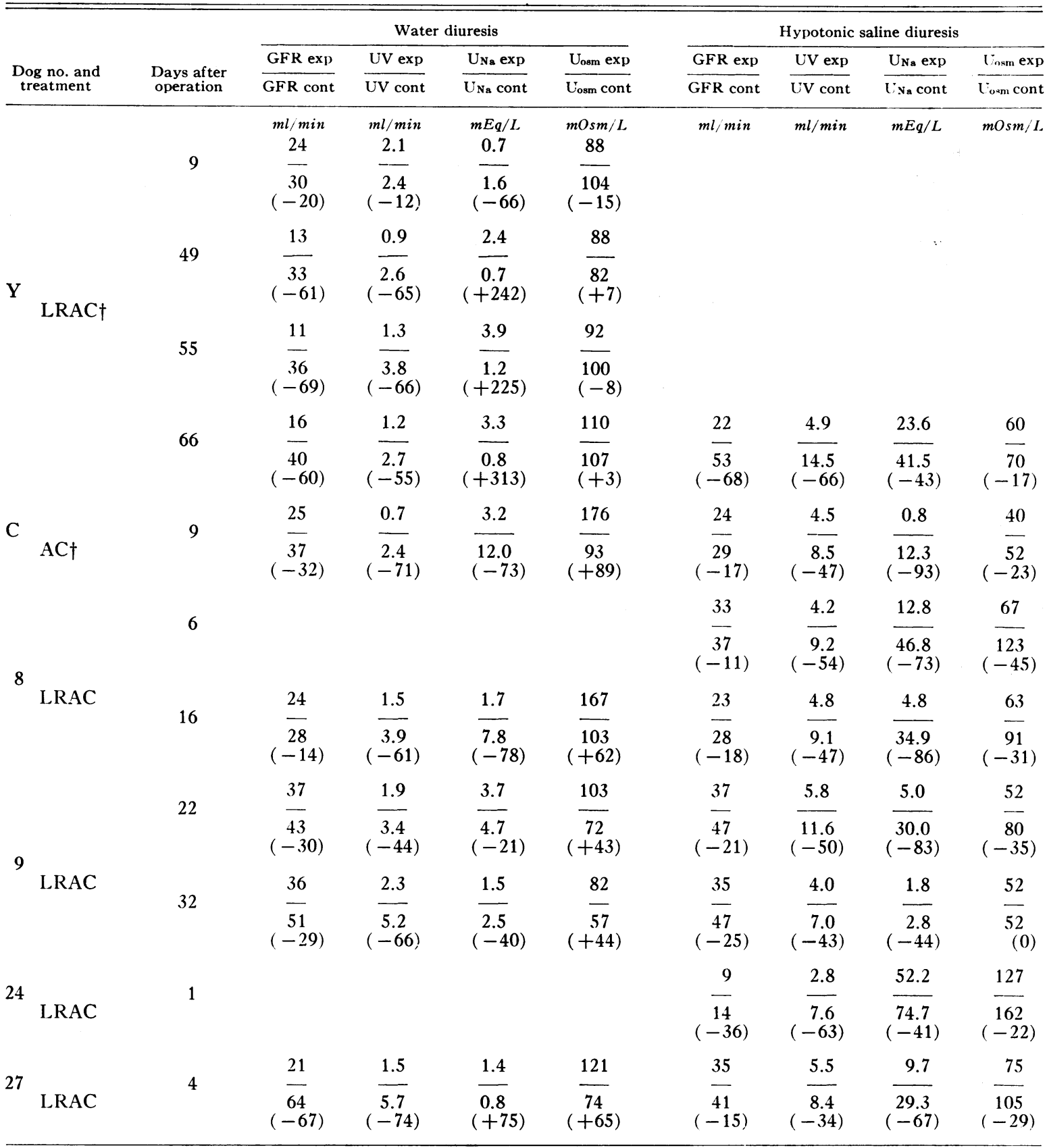

* Numbers in parentheses are the percentage of difference between the experimental (exp) and the control (cont) sides. $\mathrm{UV}=$ rate of urine excretion; $\mathrm{U}_{\mathrm{osm}}=$ urine osmolality.

$\dagger$ LRAC = left renal arterial constriction.

$\ddagger \mathrm{AC}=$ aortic constriction.

was constricted. During water diuresis, a $15 \%$ reduction in GFR on the experimental side was associated with a $50 \%$ reduction in both urine flow and $\mathrm{C}_{\mathrm{H}_{2} \mathrm{O}}$. Urine sodium concentration was markedly lower on the experimental side (1.7 $\mathrm{mEq}$ per $\mathrm{L})$, as compared with the control (7.8 $\mathrm{mEq}$ per $\mathrm{L}$ ). Urine osmolality was always higher on the constricted side, ranging from 154 to 173 
mOsm per $\mathrm{L}$, while values on the control side ranged from 90 to $110 \mathrm{mOsm}$ per L. During hypotonic saline diuresis, the difference in urine sodium concentration between the two sides was amplified, whereas urine osmolality was now lower on the constricted side.

Table IV lists the data for all experiments in dogs with chronic reductions in GFR on the left side. The effect of water diuresis was examined in nine experiments on five dogs. GFR was reduced by a mean value of $42 \%$ on the constricted side. Urine flow was uniformly lower on the constricted side, the mean reduction being $60 \%$. Urine sodium concentration was higher on the constricted side in four experiments (dog $\mathrm{Y}$, days $49,55,66 ; \operatorname{dog} 27$, day 4 ) and lower in the remaining. In $\operatorname{dog} \mathrm{Y}$, where sequential studies for 66 days were obtained, the urine sodium concentration, which was initially $56 \%$ lower on the constricted side, subsequently became higher. Urine osmolality was higher on the constricted side in four dogs, whereas in four studies on dog $\mathrm{Y}$, it was approximately the same on both sides.

The effects of hypotonic saline diuresis were examined in eight studies on five dogs. GFR and urine flow were uniformly lower on the experimental than on the control side. As compared with water diuresis, hypotonic saline diuresis resulted in a much greater difference in the concentration of urine sodium between experimental and control sides. In two instances ( $\operatorname{dog} \mathrm{Y}$, day 66; dog 27 , day 4 ), the urine sodium concentration on the experimental side, which was higher than on the control side during water diuresis, was markedly less than on the control side during hypotonic saline diuresis. In contrast to the finding during water diuresis, urine osmotic pressure on the contricted side was less than on the control side during hypotonic saline diuresis. This did not occur in the study on $\operatorname{dog} 9$, day 32 , which was considered unsatisfactory because of the failure to obtain adequate urine sodium excretion.

\section{Discussion}

Free water formation is generally assumed to result from the reabsorption of sodium salts at a relatively water-impermeable site of the nephron (6), although, until recently, direct evidence in support of this concept had been lacking. The micropuncture studies of Wirz (7), in which early distal tubular fluid was found to be hypotonic to plasma, provide strong presumptive evidence in favor of this hypothesis. Further micropuncture experiments by Gottschalk and Mylle (8) demonstrated that fluid collected from the early distal tubule was significantly more dilute when sodium chloride was infused than when mannitol or glucose was the loading solute, thereby indicating that sodium chloride reabsorption in the water-impermeable segments is the primary process in urine dilution.

The formation of solute-free water is not the only factor determining urine hypotonicity. Even in the absence of antidiuretic hormone some of the water freed by solute reabsorption is lost by back-diffusion out of the distal nephron, so that bladder urine, although very dilute, is less hypotonic than is distal tubular fluid. Gottschalk (9) has demonstrated that infusion of saline in rats with diabetes insipidus results in fluid/plasma osmolality ratios of 0.2 to 0.3 throughout the distal tubule and final urine/plasma osmolality ratios of 0.4 to 0.6 . The stop-flow experiments of Kiil and Aukland (10) during water diuresis, in which significant increases in urine creatinine concentration and osmolality occurred in areas corresponding to the collecting ducts, provide further evidence for the back-diffusion of solute-free water. The osmotic pressure, then, of the final urine, even in the absence of $\mathrm{ADH}$ activity, is dependent on the net difference between free water formation and free water back-diffusion.

Reduction in GFR during water diuresis might alter the balance of free water formation and free water back-diffusion in at least two ways. First, free water formation might be reduced because of diminished delivery of sodium to the distal nephron, ${ }^{1}$ either in proportion to or in excess of the reduction in GFR. Second, a fall in GFR also slows the linear flow of tubular fluid. Diminution in the rate of tubular flow, by allowing greater contact time with tubular surfaces, may increase both free water formation (provided sufficient sodium is present in the diluting segment) and free water back-diffusion per unit volume of tubular fluid, although in absolute terms both values may be drastically reduced.

1 The term "distal nephron" is used to designate the segments of the nephron relatively impermeable to water in the absence of antidiuretic hormone. 
Therefore, urine osmolality might rise, remain unchanged, or fall in response to a reduction in GFR during water diuresis, depending upon the relative magnitude of free water formation and free water loss.

Previous studies, in which the relationship of GFR and urine osmotic pressure during maximal suppression of $\mathrm{ADH}$ activity was examined, have yielded conflicting results and varied interpretations. Berliner and Davidson (1), del Greco and de Wardener (2), and Kleeman and colleagues (3) demonstrated that acute reduction in GFR during water diuresis was associated with the production of hypertonic urine. Berliner and Davidson (1) proposed that a reduction in GFR, by severely restricting the delivery of sodium to the diluting segment, markedly reduced free water formation. Consequently, a smaller volume of less dilute fluid was presented to the final segment of the nephron responsible for urine concentration. If this portion of the tubule remained partially permeable to water, even in the absence of $\mathrm{ADH}$, only a small volume of residual water needed to be removed to render the urine hypertonic. Leaf and his associates (4), in studies similar in design to those of Berliner and Davidson (1) and del Greco and de Wardener (2), found that a reduction in GFR had no significant effect on urine osmolality.

We found the response of urine osmolality to reductions in GFR to be related to the quantity of sodium in the urine; osmolality rose when the rate of sodium excretion was low (water diuresis) and fell when the rate of sodium excretion was high (hypotonic saline diuresis). Table II demonstrates that after acute reductions in GFR, urine osmolality uniformly rose during water diuresis and fell during hypotonic saline diuresis. In the chronic studies (Table IV) urine osmolality was higher on the constricted side in seven of nine studies during water diuresis and lower on the constricted side in seven of eight studies during hypotonic saline diuresis. This suggests that the relative rate of free water formation and free water back-diffusion during slow flow is determined by the availability of sodium salts at the diluting segment.

During water diuresis, therefore, reduced GFR allows more time for the generation of free water per unit volume of tubular fluid, but the inade- quate supply of sodium in the distal nephron severely limits this process. However, back-diffusion of solute-free water per unit volume of tubular fluid is accelerated by the slow flow, resulting in an increase in urine osmolality.

During hypotonic saline diuresis, the urine excretion of sodium is maintained despite sharp reductions in GFR (in contrast to the virtually saltfree urine excreted during water diuresis). Indeed, in some animals, as is illustrated in Tables I and III, the excretion of sodium is equal to or greater during hypotonic saline diuresis when the GFR is reduced than during control studies with water diuresis when the GFR is normal. Clearly, then, under these conditions, large amounts of sodium pass through the diluting segment, and free water formation is not restricted as it is in water diuresis, despite comparable reductions in GFR. Thus, during the infusion of hypotonic saline, a decrease in GFR causes a greater increase in free water formation per unit volume of tubular fluid than free water loss; the net result is a decrease in urine osmolality.

In contrast to the foregoing analysis, a very important role in accounting for the high rate of free water formation during hypotonic saline infusions has been assigned to the osmotic restraint imposed on free water back-diffusion by the unreabsorbed sodium salts. Since increases in $\mathrm{C}_{\mathrm{H}_{2} \mathrm{O}}$ correlated well with increases in total solute excretion, Orloff and Walser (11) attributed a large part of the increase in $\mathrm{C}_{\mathrm{H}_{2} \mathrm{O}}$ to inhibition of the back-diffusion of freed water by unreabsorbed urinary solute.

In our studies inhibition of back-diffusion of water by unreabsorbed solutes cannot account for the augmented $\mathrm{C}_{\mathrm{H}_{2} \mathrm{O}}$. When GFR is normal, $\mathrm{C}_{\mathrm{H}_{2} \mathrm{O}}$ does increase directly with increases in osmolar clearance $\left(\mathrm{C}_{\mathrm{osm}}\right)$, both during water diuresis and hypotonic saline diuresis (Figure 1). When GFR was reduced, however, the relationship was markedly altered (Figure 2 ). $\quad \mathrm{C}_{\mathrm{B}_{2} \mathrm{O}}$ per unit $\mathrm{C}_{\text {osm }}$ was enhanced during hypotonic diuresis (Figure 2, closed circles) and diminished during water diuresis (Figure 2, open circles). This suggests that for any given rate of solute excretion, $\mathrm{C}_{\mathrm{H}_{2} \mathrm{O}}$ is much greater when the principal urine solutes are sodium salts. These results are in substantial agreement with those of Burg, Papper, and Rosenbaum (12). The principal determinant of free 
water formation is clearly the delivery of sodium to the diluting segment.

Apparently, therefore, a rise in urine osmotic pressure during water diuresis is not a necessary consequence of renal hypoperfusion. The foregoing analysis clearly establishes that the osmotic pressure of the urine may rise or fall with the same reduction in GFR, depending on the availability of sodium at the diluting sites.

In addition to an elevated urine osmotic pressure, a low concentration of urine sodium has also been regarded as an important consequence of renal hypoperfusion, both in the experimental animal and in man. The results, however, have not been entirely uniform. Mueller, Surtshin, Carlin, and White (13) were able to demonstrate in dogs with split bladders and unilateral renal arterial constriction undergoing water diuresis that small reductions in GFR were associated with disproportionate reductions in urine sodium concentration. However, in patients with partial renal arterial constriction, the concentration of sodium on the ischemic side has not been uniformly depressed $(5,14,15)$. The present experiments provide a framework by which these apparent discrepancies may be resolved. During water diuresis, when sodium excretion was quite low, acute reductions in GFR produced very small

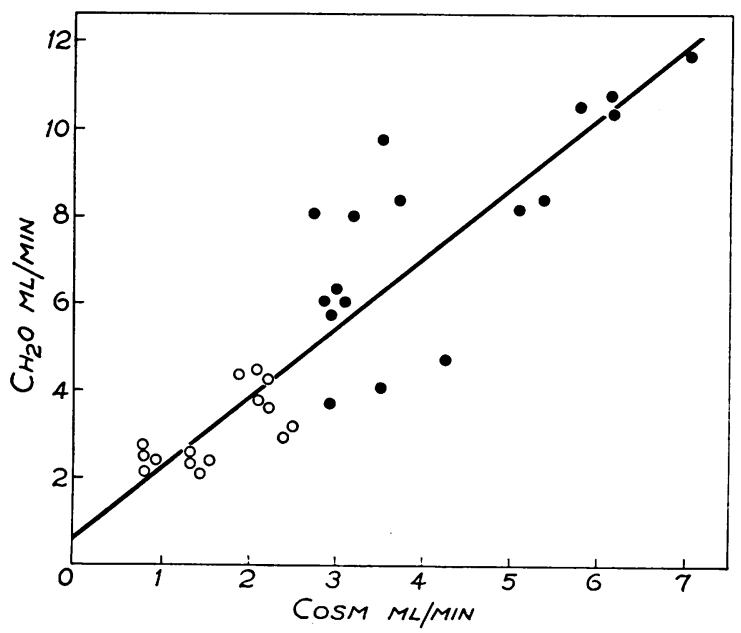

Fig. 1. Relationship of Clearance of SOlUte-free WATER $\left(\mathrm{C}_{\mathrm{H}_{2} \mathrm{O}}\right)$ TO OSMOLAR ClEARANCE ( $\mathrm{C}_{\text {osm }}$ ) DURING WATER AND HYPOTONIC SALINE DIURESIS WHEN GFR IS NORMAL. Open circles represent values during water diuresis, and closed circles represent values during hypotonic saline diuresis.

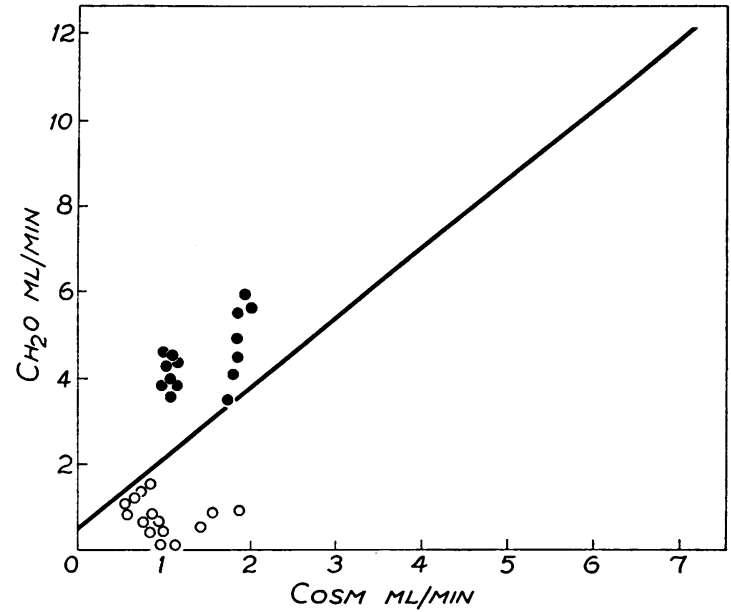

Fig. 2. Relationship of $\mathrm{C}_{\mathrm{H}_{2} \mathrm{O}}$ to $\mathrm{C}_{\text {osm }}$ during water AND HYPOTONIC SALINE DIURESIS WHEN GFR IS REDUCED. The symbols are the same as in Figure 1; the heavy line is the same regression line as in Figure 1.

changes in urine sodium concentration (a mean decrease of $1.2 \mathrm{mEq}$ per $\mathrm{L}$ ). Chronic reductions in GFR failed to consistently reduce urine sodium concentration; indeed, in four of nine studies it was actually higher on the constricted side (Table IV). On the other hand, hypotonic saline diuresis uniformly resulted in a lower sodium concentration after reduction in GFR during both acute (Table II) and chronic (Table IV) studies.

It seems reasonable to attribute the minimal reduction in urine sodium concentration when GFR is reduced during water diuresis to the limited amounts of sodium that reach the diluting segment. In consequence, slow flow cannot augment sodium reabsorption greatly, and urine sodium concentration remains unchanged or falls only slightly. During the infusion of hypotonic saline, however, sodium reaches the diluting segment in abundance, and slow tubular flow, by enhancing distal sodium reabsorption per unit volume of tubular fluid, greatly augments free water formation, thereby resulting in very sharp reductions in urine sodium concentration. The failure to observe uniformly a significant reduction in urine sodium concentration during renal hypoperfusion in experimental animals and man may be attributable, in part at least, to low rates of sodium delivery to the distal nephron. Infusion of hypotonic saline consistently discloses a depression in urine sodium concentration that may be inapparent with water diuresis alone. 
In the foregoing analysis the fall in both urine sodium concentration and osmotic pressure when the GFR is reduced during hypotonic saline diuresis has been attributed to the slow flow of tubular fluid through the diluting segment, in consequence of which sodium reabsorption and free water formation are increased per unit volume of tubular fluid. Slow flow, however, cannot account for the urine osmotic pressure's being lower during the periods of hypotonic saline diuresis plus aortic constriction than during the periods of water diuresis without constriction. In these studies urine volume was higher during hypotonic saline diuresis plus constriction than during water diuresis alone (Table II, dogs 10, 11, and $\mathrm{R}$; Table IV, dogs Y-66, C, 8, 9-22). Since urine volume, under conditions of maximal suppression of antidiuretic hormone, can be regarded as a rough approximation of the rate of flow through the diluting segment, some explanation other than flow rate obviously must account for the difference in osmotic pressure. The decreased excretion of urea, as a result of reduced $\mathrm{GFR}$, is almost certainly responsible for the lower urine osmotic pressure during hypotonic saline diuresis plus hypoperfusion.

\section{Summary}

The effects of acute and chronic reductions in glomerular filtration rate (GFR) on the urine excretion of solutes and water were studied in dogs during water diuresis and hypotonic saline diuresis. In animals with renal hypoperfusion, the different effects of water diuresis and hypotonic saline diuresis are attributable to differences in the relative rates of free water formation and free water back-diffusion. During water diuresis, slowed tubular flow secondary to reduced GFR augments free water back-diffusion disproportionately to free water formation (since sodium is virtually absent from the urine), and urine osmolality rises although urine sodium concentration may not fall. During hypotonic saline diuresis, free water formation is relatively unrestricted (since sodium is now readily available for reabsorption in the diluting segment), and reduced tubular flow augments free water formation disproportionately to free water back-diffusion; consequently urine osmolality and urine sodium concentration fall.

\section{References}

1. Berliner, R. W., and D. G. Davidson. Production of hypertonic urine in the absence of antidiuretic hormone. J. clin. Invest. 1957, 36, 1416.

2. Del Greco, F., and H. E. de Wardener. The effect on urine osmolarity of a transient reduction in glomerular filtration rate and solute output during a water diuresis. J. Physiol. 1956, 131, 307.

3. Kleeman, C. R., M. H. Maxwell, and R. E. Rockney. Mechanisms of impaired water excretion in adrenal and pituitary insufficiency. I. The role of altered glomerular filtration rate and solute excretion. J. clin. Invest. 1958, 37, 1799.

4. Leaf, A., W. S. Kerr, Jr., O. Wrong, and J. Y. Chatillon. Effect of graded compression of the renal artery on water and solute excretion. Amer. J. Physiol. 1954, 179, 191.

5. Walser, M., D. G. Davidson, and J. Orloff. The renal clearance of alkali-stable inulin. J. clin. Invest. 1955, 34, 1520.

6. Smith, H. W. The fate of sodium and water in the renal tubules. Bull. N. Y. Acad. Med. 1959, 35, 293.

7. Wirz, H. Der osmotische Druck in den corticalen Tubuli der Rattenniere. Helv. physiol. pharmacol. Acta 1956, 14, 353.

8. Gottschalk, C. W., and M. Mylle. Micropuncture study of the mammalian urinary concentrating mechanism: Evidence for the countercurrent hypothesis. Amer. J. Physiol. 1959, 196, 927.

9. Gottschalk, C. W. Micropuncture studies of tubular function in the mammalian kidney. Physiologist 1961, 4, 35.

10. Kiil, F., and K. Aukland. Renal tubular localization of water and sodium reabsorption in antidiuresis and water diuresis. Scand. J. clin. Lab. Invest. 1960, 12, 277.

11. Orloff, J., and M. Walser. Water and solute excretion in Pitressin-resistant diabetes insipidus (abstract). Clin. Res. Proc. 1956, 4, 136.

12. Burg, M. B., S. Papper, and J. D. Rosenbaum. Factors influencing the diuretic response to ingested water. J. Lab. clin. Med. 1961, 57, 533.

13. Mueller, B., A. Surtshin, M. R. Carlin, and H. L. White. Glomerular and tubular influences on sodium and water excretion. Amer. J. Physiol. 1951, 165, 411.

14. Birchall, R., H. M. Batson, and C. B. Moore. Hypertension due to unilateral renal arterial obstruction: preliminary observations on the contribution of differential renal clearance studies. Amer. Heart J. 1958, 56, 616.

15. Schlegel, J. U., E. D. Savlov, and F. Gaboa. Some studies in renal hypertension. J. Urol. (Baltimore) 1959, 81, 581. 